\title{
MAPAS DE UM PERCURSO CONSTRUÍDO POR CRIANÇAS DE 8 ANOS: INTERAÇÕES E APRENDIZAGENS LÓGICO-ESPACIAIS
}

\author{
Jussara Martins Albernaz*
}

RESUMO: Estudamos aprendizagens lógico-espaciais em atividades de construção de mapas realizadas por sete crianças de 8 anos, da segunda série de uma escola pública. Entre os teóricos que nortearam nossa investigação destacamos os da escola de Genebra (PIAGET; INHELDER,1947) e da escola russa (VYGOTSKY, 1989). Atividades lúdicas preparatórias envolveram representação de formas, montagem de quebra-cabeças, exploração de mapas, de plantas de imóveis, etc. A representação do caminho até a escola foi desenvolvida em três sessões. Crianças caminharam, discutindo e construindo individualmente um mapa. As ações foram filmadas. Após construção coletiva no quadro-negro, mediadas por educadores, os mapas individuais foram refeitos. As crianças desenvolveram capacidade notável de ler e representar mapas. A construção de conceitos espaciais e interações foram analisadas. Palavras-chave: Construção de Mapas por Crianças; Mediação e Aprendizagem LógicoEspacial; Ensino e Aprendizagem da Geometria.

\section{MAPS DRAWING BY 8-YEAR-OLD CHILDREN: INTERACTIONS AND LOGICAL-SPACE LEARNING}

ABSTRACT: TThis paper studied logical-space learning through activities of map drawing by 7 eight-year-old children of a public school. Amongst the theoreticians who guided our inquiry we point out those of the Geneva school (PIAGET; INHELDER, 1947) and of the Russian school (VYGOTSKY, 1989). Preparatory playful activities involved the representation of forms, puzzle fitting, maps exploration and etc. The representation of the path to the school was developed in three sessions. The children walked, discussing and drawing their individual maps. All their actions were shot. After a collective construction on the blackboard, mediated by educators, the individual maps were remade. The children developed great ability to read and represent maps. Their awareness of spatial concepts and interactions were analyzed.

Keywords: Maps drawing by Children; Mediation and Logical-Space Learning; Education and Geometric Learning.

\footnotetext{
* Doutora em Psicologia Escolar e do Desenvolvimento Humano pela Universidade de São Paulo (USP); Pós-Doutorado em Educação pela Faculdade de Educação da Universidade de São Paulo (USP); Professora Voluntária do Programa de Pós-Graduação em Educação da Universidade Federal do Espírito Santo (UFES).E-mail: albernaz.vix@terra.com.br
} 


\section{Objetivos e pressupostos}

Estudos atuais, baseados em pressupostos construtivistas, indicam que o ensino de geometria no ensino fundamental deve apoiar-se em intuições, nas representações naturais do aluno, na experimentação, no emprego de analogias, destoando das propostas mais tradicionais de abordagem da geometria escolar. Alguns desses estudos, inspirados nos de Piaget e Inhelder (1947) ou em outros pesquisadores da escola de Genebra, exploram dificuldades que os aprendizes precisam superar para ter acesso a diferentes conceitos da geometria: reta, ângulo, distância, área, volume, polígonos, etc. Estudos norte-americanos, como os de Minsky (1989), teorizam sobre a organização dos conceitos na mente: para este autor, os conceitos estariam conectados uns aos outros de forma nãolinear, como se fossem nós de uma rede. Essa ideia, bem-aceita hoje, tem contribuído para a construção de metodologias de ensino flexíveis. Trabalhos oriundos de outras orientações teóricas, como a sócio-histórica vygotskyana, por sua vez, têm colaborado no sentido de impulsionar novas propostas de ensino em diferentes áreas, inclusive na de educação matemática, destacando o papel do educador no processo de ensino e aprendizagem.

Tais estudos contribuíram sob diferentes formas para o presente estudo, mesmo porque admitimos, como Pozo (1989), que o pressuposto construtivista de aprendizagem pode se beneficiar de estudos oriundos de outras abordagens, que precisariam se integrar a um novo modelo teórico a ser construído, visando a aumentar nosso entendimento dos processos de ensinar e aprender. Indicações nesse sentido, no entanto, são aqui apenas sugeridas, observada a natureza empírica e exploratória do presente estudo. Adicionamos a ele uma dimensão lúdica, cuja eficácia educacional, há muito debatida no campo da Psicologia e da Pedagogia, foi comprovada empiricamente em trabalhos anteriores (ALBERNAZ; COSTA; SANTOS, 2003).

Convém esclarecer que estudos sobre como as crianças pensam e representam o mundo e o espaço geográfico que as cercam e formas de abordagem do tema pela escola têm certa conexão com o nosso (ver CASTROGIOVANNI; COSTELLA, 2006). Neste estudo, porém, exploramos, sobretudo, o aprimoramento da capacidade da criança de ler e representar mapas, que possam servir de guia para outras e refletir sobre 
relações geométricas importantes dos mesmos. A brincadeira de "mapa do tesouro", por exemplo, exige tal habilidade, pouco desenvolvida até mesmo em estudantes universitários, como mostra a avaliação de leituras de mapas de cidades que fazemos há anos com estudantes de Pedagogia, futuros professores das séries iniciais. Uma linha de investigação próxima a nossa é a da cartografia escolar, discutida por Almeida, R. D (2004). Nosso estudo, no entanto, relaciona-se mais diretamente ao ensino da geometria nas séries iniciais.

Este estudo de caso foi desenvolvido no âmbito de um projeto de extensão e de pesquisas mais amplo relativo a atividades lúdicas voltadas para as primeiras aprendizagens de elementos de geometria: jogos com formas geométricas, jogos de localização espacial, brincadeiras que exigem medição de comprimento, montagens de quebra-cabeça, etc. Analisamos seu efeito junto a crianças de 7 e 8 anos: conflitos, dificuldades, aprendizagens e o papel do mediador nesse processo.

O estudo, denominado "Aprendizagem das primeiras noções lógico-espaciais através de jogos", foi subdividido em dois subtemas: 1) "Um estudo sobre formas geométricas" - trabalho de Iniciação Científica (OLIVEIRA; ALBERNAZ, 2003); 2) "Construção de mapas e maquetes e medições de comprimento".

O segundo subtema foi subdividido em três outros: o de construção de uma maquete, já divulgado em evento (ALBERNAZ et al., 2005), o de medições de comprimento e busca do tesouro; o de elaboração de mapas. Analisaremos apenas a construção do mapa de um percurso percorrido até a escola por crianças de 8 anos da segunda série de uma escola pública (terceira série no modelo atual da Prefeitura de Vitória), projeto desenvolvido fora do horário escolar.

Destacamos algumas atividades preparatórias que contribuíram para o bom êxito da tarefa, além de aprendizagens e interações ocorridas entre os diferentes sujeitos envolvidos. O estudo traz luzes sobre novas formas de abordar o ensino da geometria no ambiente escolar.

Um dos pressupostos desses trabalhos foi o de que a compreensão do espaço geométrico requer conhecimentos do espaço de locomoção do próprio sujeito (sua frente, seu lado direito, etc.) e do espaço geográfico, onde ele e os outros se situam. Os conceitos espaciais, por outro lado, resultariam de uma construção por parte do aprendiz, que interiorizaria ações efetivamente realizadas, através de um longo processo 
de assimilações, acomodações, rupturas e reequilibrações, conforme preconizam estudos piagetianos já clássicos (PIAGET; INHELDER, 1947; PIAGET; INHELDER; SZEMINSKA, 1948).

Buscamos inspiração para este trabalho, por outro lado, em estudos teóricos e empíricos sobre a aquisição de conhecimentos geométricos, por parte de crianças e adultos, que subsidiaram uma tese de doutorado no IPUSP (ALBERNAZ, 1998) ${ }^{1}$. Os resultados daquele trabalho pareciam mostrar que a conceituação geométrica dependia de conhecimentos factuais previamente acumulados, além de estratégias heurísticas ou lógicas de abordar os problemas espaciais. Mecanismos de natureza mais analógica ou mais lógica se inter-relacionavam de múltiplas maneiras, mobilizando no aprendiz uma intensa atividade de formulação e testagem de hipóteses e produzindo reestruturações conceituais. Esses resultados se compatibilizam, por sua vez, com a ideia de que o sujeito seria um reconstrutor de conceitos culturalmente já elaborados ou um construtor de novos conceitos, que teriam de se ajustar ao seu próprio universo conceitual interno e ao universo físico e social ao qual se aplicam, mediante um processo de interação do sujeito com diferentes atores.

Da teoria dos campos conceituais de Vergnaud (1993), buscamos a ideia de que os conceitos seriam sempre adquiridos a partir de situações-problema, sendo constituídos pelos referentes (situação aos quais se aplicam), por significados (esquemas resultantes de ações interiorizadas) e significantes (representações simbólicas) que ganham complexidade ao longo do desenvolvimento. Daí a importância de atividades de natureza representativa articuladas a ações efetivamente realizadas pelas crianças em contexto significativo.

Integramos a essa ideia aportes de Vygotsky (1989), que afirma que os conceitos científicos dependem fundamentalmente da instrução para serem elaborados. Nas atividades propostas, o educador atua como organizador de atividades, mediador de dificuldades e formulador de pequenos problemas. As crianças são estimuladas a trocar ideias umas com as outras, a experimentar e testar hipóteses.

A adoção desses pressupostos nos levou à necessidade de tomar situações da vida real como ponto de partida para viabilizar a construção de diferentes noções espaciais. A observação da vida infantil, por sua vez, mostra o papel importantíssimo que nela ocupam o jogo e a brincadeira, estudados por diferentes correntes do pensamento. Tais atividades lúdicas 
favoreceriam o desenvolvimento cognitivo da criança e ajudariam na construção de sua subjetividade e na sua socialização.

Por entendermos que as atividades de construção de conceitos e de solução de problemas são solidárias e que a criança aprende a resolver problemas brincando, integramos a dimensão lúdica às atividades propostas e analisamos seus efeitos.

\section{Método}

A natureza da pesquisa foi qualitativa, caracterizando-se como um estudo de caso que envolvia crianças e educadores. Observamos e analisamos atividades preparatórias e o processo de construção de mapas pelas crianças em atividades individuais e coletivas, com técnicas de coleta e de análise de dados variadas, sintetizadas adiante.

\section{Sujeitos}

Um grupo de dez crianças que cursavam o final da segunda série de uma escola pública situada no campus da UFES foi atendido em atividades realizadas fora do horário escolar, sendo elas submetidas aos estudos relativos ao reconhecimento e à construção de mapas, no âmbito de um projeto de extensão do NIEPACIS ("Jogos matemáticos nas primeiras séries”). Sete deles participaram integralmente das atividades de construção do caminho até a escola, relatada adiante: três meninos e quatro meninas

Três graduandos de Pedagogia, uma mestranda de educação e a experimentadora participaram da coleta de dados, interagindo com as crianças e analisando os dados.

\section{Coleta e análise dos dados}

A coleta de dados foi feita por meio de observação participativa, diário de campo, filmagens e produções das crianças. A análise apoiou-se: (1) nas anotações dos diferentes observadores discutidas coletivamente; (2) nas imagens produzidas pelas crianças (desenhos) ou obtidas por meio de filmagens; (3) no processo de produção das crianças observado nas diferentes etapas do projeto (interações, dificuldades, etc.). 


\section{Atividades preparatórias:}

\section{familiarização com mapas, plantas e medidas de comprimento}

A maioria das crianças examinadas na atividade de construção de mapas já havia participado de atividades lúdicas por dois meses (com duração semanal de uma hora e meia), envolvendo diferenciação de formas com blocos lógicos, montagem de quebra-cabeças, tangran, desenho do "círculo perfeito" suscitado pelo filme Donald no país da Matemática (produção de relógios analógicos), etc. A capacidade de análise das formas submetidas a rotações e de representação das mesmas havia sido, assim, bastante estimulada, pois estudos anteriores (ALBERNAZ, $1980)^{2}$ mostravam não só as dificuldades, mas a importância desse tipo de atividade para a elaboração de conceitos espaciais.

As crianças foram apresentadas igualmente a diferentes mapas da cidade de Vitória (mapas turísticos e de ruas, mais fantasiosos ou com medidas mais exatas), além de mapas rodoviários do Espírito Santo e plantas de apartamentos, sendo desafiadas a simular diferentes trajetos que poderiam seguir para ir de um ponto a outro da cidade e analisar as características dos mapas apresentados. Desenharam também seu quarto, cuja representação retangular não fora logo entendida (o contorno era irregular, mostrando detalhes como cama, armários e a área de movimentação no interior do quarto), além do prédio do Centro de Educação (ver desenho feito por uma das monitoras - Fig.7).

A justificativa teórica para a escolha das atividades de familiarização com diferentes mapas adveio de estudos de Bresson (1976), que ressalta que diferentes representações figurativas de um mesmo objeto (planificações do cubo, sua representação em perspectiva, etc.) ou de um conjunto de objetos destacam certas propriedades e omitem outras, o que é ressaltado também no modelo de Vergnaud (1993). Observa-se, assim, que um mapa turístico realça pontos interessantes para serem visitados (igrejas, palácio, parques) e omite casas, árvores, plantas, etc. Alguns mapas apresentam todas as ruas, outros omitem algumas delas, embora sua ordem de posição relativa não possa ser alterada, uma vez escolhido um sentido de exploração (propriedade essencial do mapa). Daí a necessidade de utilizar representações variadas de mapas para que o aprendiz se torne capaz de representar um caminho a ser percorrido por outro e aumente sua habilidade de ler mapas. 
Outra atividade desenvolvida foi inspirada em um jogo industrial (da Estrela, fábrica de brinquedos) relativo a sinais de trânsito, que teve algumas regras alteradas por nós a partir de estudos feitos anteriormente com crianças de primeira e segunda séries. No jogo modificado, a criança se movimenta na planta de uma cidade (em papel-cartão) com a ajuda de dados, usando pequenos carrinhos, observando aos sinais de mão e contramão, aprendendo sobre sinais de trânsito, fazendo cálculos de multas ou de perdas de pontos na carteira de motorista. A criança familiariza-se, assim, com o mapa de uma cidade e aprende a escolher o menor percurso viável, respeitando as regras de trânsito.

Além disso, foi desenvolvido como atividade complementar um jogo de adivinhação, opondo meninos e meninas, que envolvia desenhos feitos por eles no interior de retângulos pré-desenhados pela experimentadora, com diferentes medidas de comprimento e de largura. O time adversário precisava adivinhar onde estava certo desenho, referindo-se às medidas do retângulo feitas com uma régua. Procurava-se envolver, assim, as crianças em atividades de comparação de comrimento, conceito que ainda não dominavam e era necessário na atividade de "caça ao tesouro" que se seguiria à de construção de mapas (pré-teste piagetiano clássico de conservação de comprimento fora aplicado anteriormente: a mudança de posição ou o movimento de um segmento rígido interferia na avaliação de seu comprimento - a criança - julgava que este aumentava com relação a outro mantido imóvel).

Vamos apresentar, mais detalhadamente, apenas a atividade de construção do caminho até a escola, desenvolvida logo após as atividades citadas.

\section{A construção do caminho até a escola: percalços e resultados}

É importante ressaltar que o percurso percorrido pela criança até a escola não podia ser visualizado por inteiro, pois havia imóveis e árvores na área, além de curvas. Ademais, havia mais de um caminho possível para se chegar até lá (ver mapa, distribuído pela UFES em 2001, com o caminho percorrido - Fig.4; o mapa atual do campus tem a medida do trajeto de aproximadamente $700 \mathrm{~m}$, calculada pelo Google 2009 - Fig.6). A 
título de incentivo foi discutido com as crianças que a atividade de construção de mapas aumentaria a possibilidade de construírem seus próprios mapas, não só para que outros pudessem segui-los e encontrar o caminho que deveriam percorrer, mas também para poderem brincar de caça ao tesouro, uma atividade que se seguiria àquela.

\section{Atividades pedagógicas}

A atividade foi realizada em três sessões diferentes:

- Percurso do caminho até a escola, fazendo anotações e construindo um mapa inicial;

- Elaboração de um mapa individual após construção coletiva de um mapa no quadro-negro, com o apoio nas anotações de cada um;

- Aperfeiçoamento do mapa individual.

\section{Primeira sessão:}

\section{caminhada e representações do percurso}

$\mathrm{Na}$ primeira sessão, foram dados a cada criança uma folha grande de papel almaço duplo, um lápis e uma borracha, e foi discutido que deveriam parar em diferentes pontos do trajeto para poderem desenhá-lo. Foi-lhes explicado que os detalhes não deveriam aparecer no mapa, apenas o trajeto com os principais imóveis, para melhor orientar a pessoa que fosse percorrê-lo com o apoio do mapa. Durante o trajeto, as crianças contaram com o apoio de monitores $^{3}$, cuja função era cuidar para que nada lhes acontecesse (havia uma estrada no interior do campus onde podiam circular alguns carros), incentivá-las e orientá-las quando solicitassem ajuda. A coordenadora do projeto acompanhou as crianças, filmando alguns momentos da caminhada e das paradas (foram 6), quando as crianças desenhavam parte do percurso. Procurou-se captar as principais dificuldades surgidas, se elas eram superadas e como, as interações e mediações viabilizavam a realização da atividade. $\mathrm{O}$ ataque de mosquitos provocou, no início do percurso, certa reclamação. Caixas de papelão desfeitas foram utilizadas como abanadores ou apoio para a atividade de desenhar. Alguns diziam ser difícil representar o que o que 
viam, mas encararam o desafio. Foi explicado mais de uma vez que os desenhos poderiam ser refeitos posteriormente, após o exame das filmagens, e que omitissem os detalhes (o importante era que outra pessoa pudesse se apoiar no desenho para sair do prédio do Centro de Educação, IC4, e ir até a escola).

Para entendermos as primeiras produções das crianças, convém relatar que a decisão de parar para desenhar sempre coincidia com alguma discussão sobre elementos do percurso: a estrada por onde passavam carros, o prédio do curso de Direito (uma criança conhecia alguém que estudava Direito), o Laboratório de Física e Química (eles conversaram com alguém do laboratório, perguntando o que faziam lá), a Biblioteca Central da UFES, etc. Os imóveis que foram objeto de discussão apareceram nos mapas e os outros, não (o pavimento diante do prédio da Caixa Econômica Federal, que não foi objeto de qualquer discussão, por exemplo, não foi desenhado por nenhuma criança). Além disso, sempre que paravam, as crianças tinham uma visão da parada anterior, o que podia garantir certa continuidade no desenho do caminho percorrido. Agrupamentos de duas a três crianças eram formados, com os meninos e as meninas normalmente em grupos separados, refeitos a cada parada.

Todos os mapas produzidos continham alguma omissão e prédios desenhados com orientações diferentes das existentes no terreno: o prédio do curso de Direito, que se situava no lado direito do caminho, por exemplo, do mesmo lado da Biblioteca Central, foi desenhado por uma das crianças no lado esquerdo, etc. Os erros eram diferentes e bem pessoais, além de não repetitivos. As meninas desenhavam com mais detalhes e, por isso, eram mais lentas. Uma delas representou inclusive um carrinho de picolé diante da CEF, próximo à escola, e uma estátua diante do prédio da biblioteca.

Outra coisa a se considerar é que para dar conta de percurso tão longo, a maioria rodou a folha em algum momento de percurso ou produziu curvas inexistentes, sobretudo diante da biblioteca, que ficava aproximadamente na metade do caminho. Sendo assim, certas partes do percurso desenhado não se justapunham a outras, embora a maioria dos prédios que foram objeto de discussão aparecesse nos desenhos. Os meninos queriam desenhar o estacionamento depois da escola e reclamaram do tamanho do papel, que, no entanto, era bem grande. 


\section{Segunda sessão:}

\section{construção coletiva do mapa no quadro-negro}

Antes da sessão de construção coletiva do mapa no quadronegro, realizada na semana seguinte, os educadores analisaram os mapas que haviam sido construídos pelas crianças durante a caminhada, em especial os acertos e desacertos do ponto de vista geométrico. A mediação pedagógica foi entendida como essencial para que as crianças tivessem êxito na tarefa de confeccionar novos mapas individuais, que conserassem a ordem dos imóveis e sua posição relativa no terreno (propriedade essencial do mapa). Folhas de papel, lápis de diferentes cores e borracha foram colocados à disposição de cada criança, além de seus próprios mapas anteriores. As mediadoras ${ }^{4}$ observavam algumas das dificuldades das crianças e anotavam as interações ocorridas durante a produção coletiva do mapa, oferecendo algumas sugestões, sobretudo ao final da sessão, quando teve início a produção individual.

A experimentadora optou por dar início à construção coletiva com o desenho de um retângulo do lado direito do quadro-negro, na parte de baixo, representando o prédio do IC4 do Centro de Educação, onde estavam as crianças. Ele aparecia de forma retangular no desenho de todas, mas sua localização variava. $\mathrm{Na}$ extremidade superior esquerda do quadro foi assinalada a escola, com uma cruz. Foi explicado, então, que se o IC4 fosse desenhado naquela posição seria possível que o percurso total coubesse no quadro-negro. Os desenhos dos prédios do IC4 e do IC3, localizados um ao lado do outro, foram feitos pela examinadora, com sugestões das crianças (perguntas feitas: de que lado fica o prédio do IC3? Como chegaram até lá? Ele é do tamanho do IC4? Como podemos desenhá-lo?). As crianças puderam, nesse momento, examinar da janela o percurso até o IC3. A partir daí deram continuidade ao desenho do mapa no quadro-negro, revezando-se na tarefa. Discutiram sobre a necessidade de desenhar a estrada (perpendicular aos prédios dos ICs) e o Laboratório de Física e Química, que aparecera em todos os desenhos, além do prédio do curso de Direito, que margeava a estrada. Foi discutido onde cada imóvel devia ser colocado (algumas crianças haviam invertido as posições nos desenhos). A experimentadora provocou uma discussão (o laboratório deve ficar deste lado da estrada ou daquele?). B. assinalou a posição do Laboratório e participou, com outra criança (C.), da discussão 
sobre a localização do pavimento do curso de Direito. Todos concordaram com a localização dos imóveis desenhados no quadro por B. O grupo discutiu sobre a Biblioteca Central, também desenhada por B. As crianças pediram que fosse aumentado seu tamanho e que fosse assinalado o estacionamento dos carros. Após algumas tentativas, a produção final da menina foi aceita por todos. Outra criança foi ao quadro desenhar o Restaurante Universitário (RU), adjacente ao espaço da biblioteca, e as pedras existentes em frente ao Banco do Brasil (BB), localizadas em um espaço arborizado que conheciam bem e que lhes agradava bastante. O BB, por sua vez, fica logo depois do Restaurante Universitário, próximo a uma curva. Houve discussão sobre a posição dos prédios do Banco do Brasil e da Caixa Econômica Federal (CEF).

Neste momento, a pesquisadora resolveu mostrar o que fora filmado. As crianças se entusiasmaram e os meninos reclamaram porque não apareceram no espaço onde há pedras e árvores (a filmagem se voltara para o RU, para o prédio do Banco do Brasil e depois para a curva, de onde se via a escola, após o imóvel da CEF). De volta ao desenho no quadro-negro, as crianças assinalaram as posições corretas do BB, das pedras e da CEF, desenhadas por C. M. reclamou da falta de espaço para o estacionamento diante da escola, o qual foi desenhado em tamanho pequeno.

As filmagens feitas na semana anterior auxiliaram na solução de conflitos. Uma só criança parecia desnorteada: a que levara o desenho para casa e se esquecera de trazê-lo de volta. Sem o próprio desenho para explorar, ela se perdia e quase não participava das discussões. Ao final da produção coletiva, uma menina, C., de 8 anos, pediu para filmar a atividade de recapitulação do trajeto, que continha nove imóveis considerados importantes pelas crianças. A experimentadora concordou e foi até o quadro. As crianças, provocadas pela experimentadora, resumiam: "saímos do IC4, contornamos o IC3", "chegamos à estrada", etc.

Algumas das perguntas feitas nesta etapa foram: "Entramos no IC3?" Todos responderam: "Não"; "Onde vocês pararam para desenhar?" As crianças apontavam os seis locais, olhando para o próprio desenho e para o quadro. A filmagem de $\mathrm{C}$ saiu muito boa, centrada no quadro-negro. Ela filmou silenciosamente. 


\section{A construção do mapa individual: \\ segunda e terceira sessões}

Após a atividade coletiva, as crianças foram para as mesas com folha de papel dupla para reproduzir o mapa do trajeto, apoiando-se no desenho feito no quadro. A primeira dificuldade foi novamente onde situar o prédio do IC4. O desenho no quadro parecia de pouca ajuda. As crianças manipulavam seus próprios mapas feitos anteriormente e pareciam perdidas. As mediadoras sugeriam que deviam começar pela extremidade direita, embaixo, como fora feito no quadro-negro. Algumas começaram a fazê-lo, sem aparentar muita dificuldade, outras pediam alguma ajuda, comparando seu mapa antigo com o do quadro-negro.

A título de ilustração de algumas dificuldades surgidas, vamos transcrever as interações surgidas entre uma criança, C., que teve dificuldades para produzir um novo mapa, e as investigadoras:

Após a atividade no quadro-negro, da qual participara até assumir a filmagem, C. ficou por longo tempo desenhando, na folha nova, o percurso entre o IC4 e o IC3, cujas posições ela havia invertido. O IC4 estava na extremidade esquerda de sua folha, o que passara despercebido pelas monitoras, que haviam orientado as crianças a começar o desenho a partir do ponto inicial (o IC4), embaixo da folha, à direita. ... C. dizia que tinha de desenhar as flores do caminho. Enquanto isso, a maioria conseguiu reproduzir o mapa do quadronegro corretamente, com algumas discrepâncias no tamanho relativo dos imóveis, mas não na posição relativa deles.

C. alegou, em dado momento, que não conseguia fazer o desenho e uma das monitoras (aluna de Pedagogia) observou que ela invertera a posição dos imóveis, mas reagia à ideia de recomeçar o desenho. Sugeriu então que ela desenhasse tudo invertido, com a escola indo para o lado direito, no alto. Ou seja, o desenho só corresponderia à realidade se fosse examinado pelo avesso. A proposta foi recusada, com ar de choro [...] A experimentadora se aproximou, ao ouvir a sugestão, que foi motivo de debate posterior do grupo (a representação de um simples caminho inverso já seria uma atividade muito complexa para crianças dessa faixa etária, que inanguravam seus primeiros passos na atividade de produção de mapas, como mostra estudo de Piaget e Inhelder sobre a representação de trajetos, já citado).

C. mostrou à experimentadora seu mapa antigo, dizendo, em tom de reclamação: "Não consigo fazer o mapa direito". No mapa, as posições do IC4 e IC3 estavam corretas, mas antes da Biblioteca Central havia uma grande ruptura que a desnorteava (O Laboratório de Física e o prédio de Direito ficaram isolados no lado esquerdo da folha, separados do trajeto). A experimentadora lhe oferecen outra folha e sugeriu que comecasse pelo lado direito, como havia feito no mapa anterior, que estava ao seu lado. Ela pareceu desanimada e disse que não queria mais fazer o mapa, porque não conseguiria. 
Um exame melhor da produção da criança indicava que, ao chegar à biblioteca, ela teria virado a folha (giro de $90^{\circ}$ para a esquerda) e continuado, ao desenhar o trajeto sem considerar sua interrupção. Na verdade, era com se existissem três porções do trajeto, justapostos, que não se encaixavam. A experimentadora disse "Você consegue sim! Tudo está no seu desenho, só que você virou a página ao desenhar os imóveis e as partes do trajeto não estão se encaixando. Se você me deixar recortar seu mapa e colá-lo sobre outra folba dupla, verá que o mapa está certinho". Após certa hesitação (ela não queria que o mapa fosse desfeito), concordou. Foi recortada a folha. A parte correspondente ao trajeto do IC4 à biblioteca foi separada do restante da folha e se imprimin ao trecho certa rotacão. Com a inserção do Laboratório de Física no meio da folha, na posição correta, e pequeno ajuste na terceira porção do mapa (da biblioteca até a escola), este ficou semelhante ao que estava no quadro. C. se animou a refazer o mapa. Disse: "Vou tentar, acho que consigo" (cópia do desenho inicial aparece no anexo, Fig.5), ou seja, foi preciso levar C. a refletir sobre sua produção, chamando a atenção para seus acertos e minimizando a importância dos desacertos, para aumentar sua autoconfiança.

O trecho acima mostra a dificuldade que representou para as crianças o desenho de um percurso tão longo (mais de $700 \mathrm{~m}$ ). O nãoajuste entre si de diferentes partes do trajeto foi uma dificuldade geral, superada graças à atividade de construção coletiva, no quadro-negro, com a mediação da experimentadora. C. teve dificuldade para refazer o mapa por não conseguir demarcar corretamente a posição inicial do percurso. Além disso, como estava filmando, não participou ativamente da recapitulação final e algumas informações lhe teriam escapado.

$\mathrm{Na}$ terceira sessão, na semana seguinte, com o desenho ainda no quadro-negro, as crianças terminaram o mapa individual após assistirem de novo às filmagens, revendo pontos do trajeto. Retomaram seus desenhos, colorindo ou fazendo neles pequenos acertos. Alguns adicionaram, inclusive, pontos não visitados naquele dia, como um pequeno lago, próximo à escola, a exemplo de M. (Fig.3). Ele disse que costumava percorrer com o pai outro percurso para chegar até a escola de carro. Explicou que desenhou o Banco do Brasil e a Caixa Econômica Federal do mesmo tamanho (o prédio da CEF era maior do que o do Banco do Brasil, mas ambos foram desenhados em tamanho bem pequeno) porque "banco é tudo a mesma coisa" (ver Fig.3). Árvores, flores, carros, etc. também apareceram nos desenhos finais da maioria. 


\section{Conclusões}

Foi analisado o processo de produção do mapa do caminho até a escola feito por crianças de 8 anos, após três sessões de atividades semanais de pouco mais de uma hora, envolvendo a exploração de um percurso possível até a escola. A caminhada foi interrompida seis vezes para a construção individual do mapa. A iniciativa das paradas foi das crianças, em função de dúvidas e discussões sobre elementos do terreno ou devido a curvas que as levavam a reexaminar o percurso já feito. Houve discussão coletiva e reconstrução do mapa no quadro-negro, seguidos de nova produção individual. Procedimentos e estratégias empregados para que chegassem a um bom termo nessa empreitada parecem mostrar que a produção final parece ter sido o resultado de:

1) Um trabalho preparatório: exploração de diferentes mapas e plantas físicas de imóveis, discussões sobre posição relativa de imóveis - direita esquerda, desenhos de plantas de suas casas, desenho do prédio do IC4 observado de fora e explorado internamente de diferentes maneiras, diferenciação de formas geométricas, medição de comprimento, etc., desenvolvidos através de atividades lúdicas. Algumas noções espaciais elaboradas nessa etapa foram fundamentais para a construção do mapa, despertando muito interesse.

2) Um trabalho de exploração física e de reflexões sobre a atividade de andar sobre um terreno e examinar suas características físicas e funcionais (o que seriam os imóveis existentes no espaço da UFES e para que serviam?), articulado a uma atividade semiótica - as crianças representavam o espaço percorrido através de um conjunto de traços e marcos do terreno (desenhavam imóveis mais significativos para elas, grandes pedras de um espaço arborizado, etc.). Esses dados reforçam um dos elementos centrais da teoria de Vergnaud (1993), segundo a qual os conceitos são sempre "operatórios" ou adquiridos através das situações e dos problemas a serem resolvidos, sendo compatíveis com os estudos recentes sobre a construção do espaço geográfico. A elaboração de um mapa que respeita relações geométricas do terreno é uma atividade simbólica que mobiliza e requer não só uma reflexão sobre o espaço geográfico a ser desenhado, mas a elaboração de diferentes conceitos espaciais (tamanho, forma e posição relativa dos imóveis; posição da estrada, perpendicular aos ICs, etc.). Representa ainda a solução de um problema complexo que as crianças reinventaram, como preconiza Pozo (2001), transformando-o em seu problema. O ponto de vista "piagetiano" de que a compreensão do espaço geométrico requer conhecimentos do espaço de locomoção do próprio sujeito (sua frente, seu lado direito, etc.) e do espaço geográfico onde ele e outros se situam e de uma atividade de reflexão sobre suas ações (virar para a direita, seguir em frente, 
etc.) também se mostrou profícuo. As respostas obtidas reforçam essa hipótese.

3) Houve, finalmente, um trabalho de mediação dos educadores que conduziu as crianças a uma reflexão, coletiva e individual, sobre propriedades importantes do percurso (sentido do movimento, ordem, importância e função dos itens desenhados e sua posição relativa, etc.) e as incentivou em seu trabalho. Isso não só ajudou as crianças no momento de produção dos mapas iniciais como, sobretudo, propiciou a reformulação dos mesmos. As filmagens ajudaram a esclarecer dúvidas surgidas. Propriedades lógicoespaciais do terreno - orientação, forma e posição dos marcos, angulação e continuidade do caminho -, inicialmente desconsideradas na representação, passaram a se incorporar aos desenhos e as crianças chegaram a mapas individuais de muito boa qualidade (Fig.1). A ação dos mediadores, como destaca Vygotsky, permitiu que as crianças avançassem na compreensão de propriedades espaciais importantes. Este estudo destacou como algumas reestruturações importantes ocorreram (ver mapas iniciais e finais de algumas crianças que aparecem nos anexos - Fig.1, Fig.2, Fig.3 e Fig.5).

Convém ressaltar também que, durante a produção coletiva no quadro-negro e mesmo no momento da produção individual, todos consultavam seus mapas iniciais. Apesar dos erros de localização de alguns imóveis, estes orientavam as crianças, seja no debate com os educadores e com as outras crianças seja nas novas produções. Uma criança que levou o mapa para casa e lá o esqueceu interagiu pouco com as outras durante as atividades coletivas no quadro-negro e enfrentou dificuldades para fazer novo mapa.

A atividade de construção do mapa do caminho constituiu excelente oportunidade para que os mediadores refletissem sobre possibilidades e dificuldades de tarefas de natureza espacial, sobre operações mentais que elas mobilizam e como crianças de 8 a 9 anos (de segunda série) podem superar as dificuldades, com uma boa orientação.

Esta atividade tornou possível a realização de inúmeras outras, como a de busca ao "tesouro", o apoio de mapas dos arredores do IC4 e de uma maquete (ALBERNAZ e outros, 2005), que geraram, por sua vez, novas aprendizagens de natureza geométrica e social - aumento da compreensão do espaço onde a escola se localiza, de aspectos do campus $\mathrm{da}$ universidade que as crianças e os educadores pouco conheciam e maior capacidade de trabalhar em equipe. 


\section{REFERÊNCIAS}

ALBERNAZ, J. M. Propriétés géométriques et classification: la similitude des triangles chez l'enfant de 6 à 11 ans. 205 p. "Mémoire" para obtenção do título de "l’Èleve Diplômé de l'École des Hautes Études en Sciences Sociales" em Psicologia do Desenvolvimento Cognitivo. Paris, E.H.E.S.S., 1980.

ALBERNAZ, J. M. Categorização das formas geométricas: do protótipo ao conceito. 385 p. Tese (Doutorado) São Paulo, Instituto de Psicologia, USP, 1998.

ALBERNAZ, J. M.; COSTA, R. C. F.; SANTOS, V. P.; ROCHA, S. M. A. Aprendizagem das primeiras noções lógico-espaciais: construção de uma maquete. In: Anais do VII Encontro de Pesquisa em Educação da Região Sudeste. Belo Horizonte, v.1, p. 12-27, 2005.

ALMEIDA, R. D. Do desenho ao mapa. Iniciação cartográfica na escola. São Paulo: Contexto, 2004

BRESSON, F. Reflexions sur les systèmes de représentation. Média, v. 1, p. 7- 13, 1975.

CASTROGIOVANNI, A. C.; COSTELLA, R. Z. Brincar e cartografar com os diferentes mundos geográficos: alfabetização espacial. Porto Alegre: EDIPUCRS, 2007.

MINSKY, M. A. A sociedade da mente. Rio de Janeiro: Francisco Alves,1989.

OLIVEIRA, V. C.; ALBERNAZ, J. M. Aprendizagem das primeiras noções lógicoespaciais através de jogos. In: Anais da XIII Jornada de Iniciação Científica. Vitória, v. 1, 2003. PIAGET, J., INHELDER, B. La représentation de l'espace chez l'enfant. Paris: PUF, 1947.

PIAGET, J.; INHELDER, B.; SZEMINSKA, A. La géométrie espontanée chez l'enfant. Paris: PUF, 1948.

POZO, J. I. Teorias cognitivas del aprendizage. Barcelona: Ediciones Morata, S.L.,1989.

POZO, J. I. (Org.) Solução de Problemas. Porto Alegre: Artmed, 2001

VERGNAUD, G. Théorie des Champs Conceptuells. Manuscrito apresentado no Congresso Internacional de Educação Matemática, Rio de Janeiro, julho 1993.

VYGOTSKY, L. S. Pensamento e linguagem. São Paulo: Martins Fontes, 1989. 


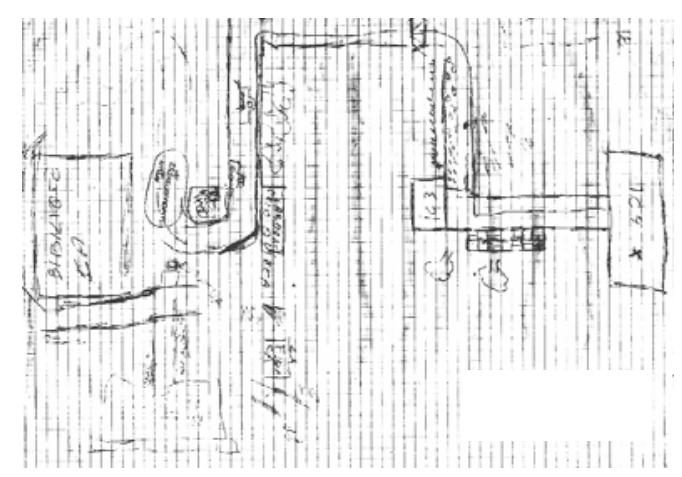

Fig.1 - Produção individual inicial de L. (8 anos, menina) (posicionamento adequado dos imóveis)

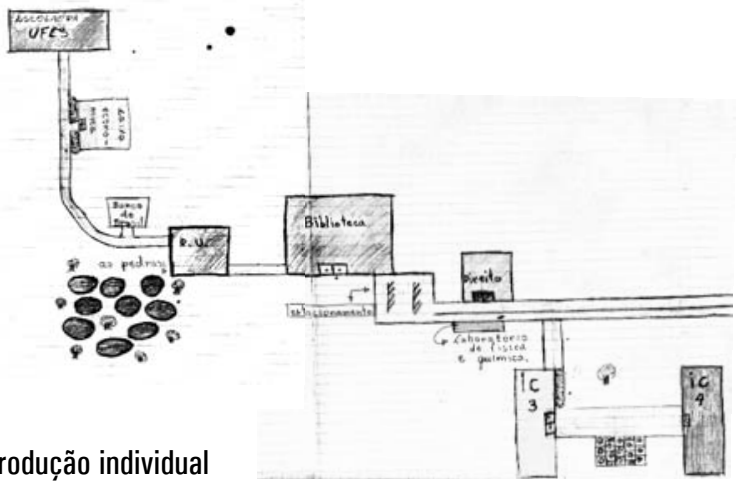

Fig.2 - Produção individual

final de L. (posicionamento adequado dos imóveis)

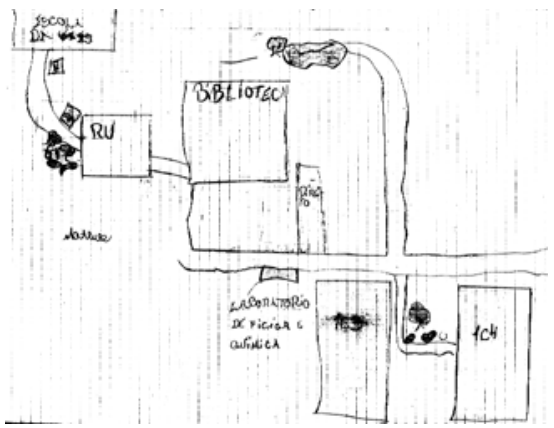

Fig.3 - Produção final de M. (8 anos, menino).

Com um pequeno lago atrás da Biblioteca Central, assinalando outro caminho possível para ir à escola. 

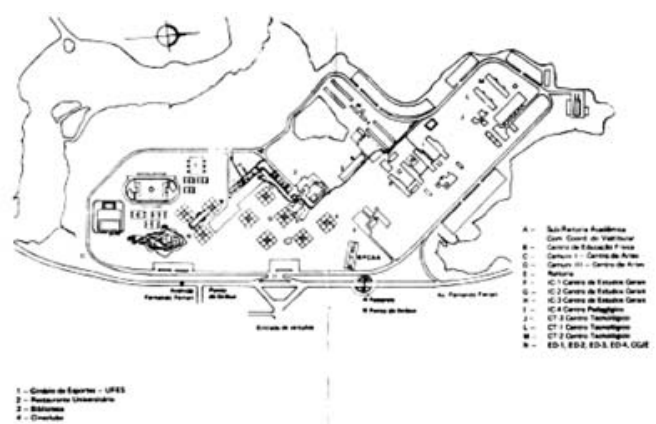

Fig.4 . Mapa do campus (UFES, 2001) com o trajeto assinalado por uma monitora em 2005. - do IC4 à escola.

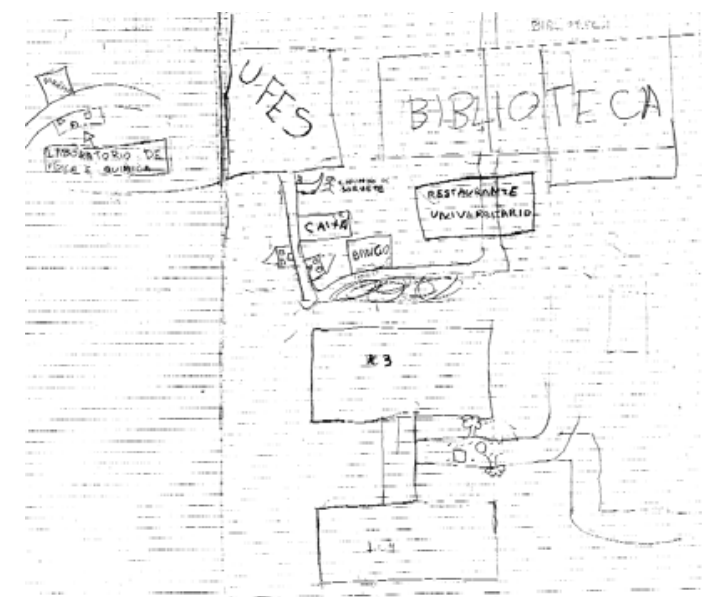

Fig.5 - Produção inicial de C. (as rotações na folha provocaram desorientação). 0 Laboratório de Física aparece à esquerda (recorte da experimentadora) e não entre o IC3 e 0 espaço diante da Biblioteca Central.

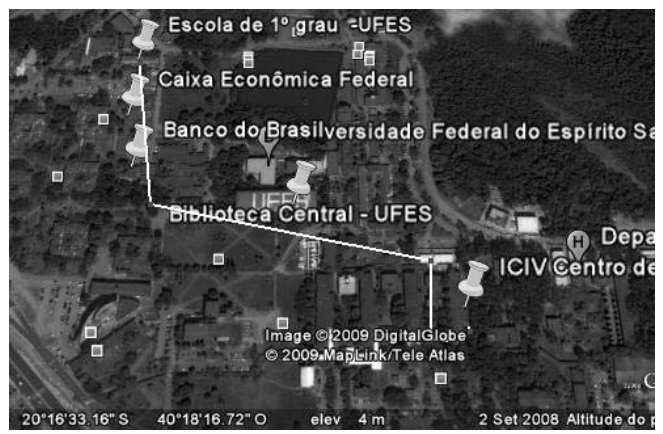

Fig.6 - Percurso do ICI4/CE à escola, marcado em branco; alguns imóveis estão assinalados com pinos amarelos (linhas retas foram usadas para o cálculo da distância aproximada - $700 \mathrm{~m}$ ). 


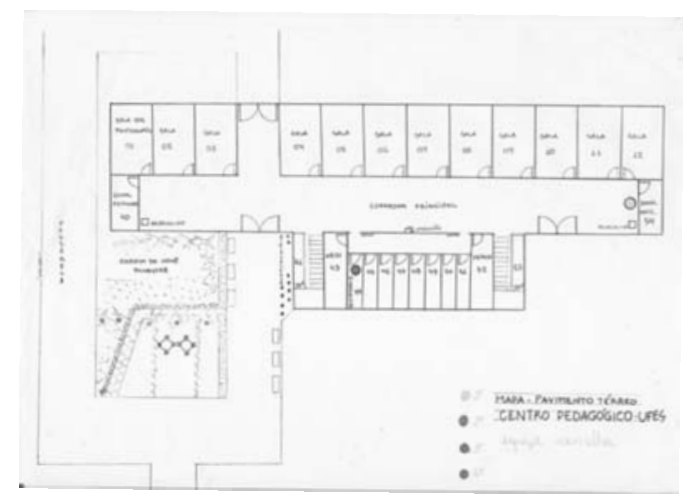

Fig.7- Prédio do IC4 (atual Centro de Educação, ex-Centro Pedagógico), de onde partiram as crianças. Desenho de Viviani C. de Oliveira, bolsista de Iniciação Científica do CNPq, do curso de Pedagogia da UFES (2004).

\section{Notas}

${ }^{1}$ Tese defendida no IPUSP sob orientação de Maria Isabel da Silva Leme.

${ }^{2}$ Estudos desenvolvidos na EHHSS de Paris, sob orientação de Pierre Greco.

${ }^{3}$ Monitores que atuaram nessa atividade: Oliveira ,V. C.; Fonseca, S. C. G.; Azevedo, A. S.

${ }^{4}$ Esta sessão contou com o apoio das monitoras já citadas e da mestranda Rocha, S.M.A.

Recebido: 24/04/08 Aprovado: 13/07/09

Contato:

Universidade Federal do Espírito Santo

Programa de Pós-graduação Av. Fernando Ferrari, s/n. Campus Universitário - Goiabeiras.

Vitória - ES CEP 26060-900 